\title{
A ÉTICA DA LIBERDADE EM KIERKEGAARD: ENTRE ANALÍTICOS E CONTINENTAIS
}

\section{ETHICS OF LIBERTY KIERKEGAARD: BETWEEN ANALYTICAL AND CONTINENTAL}

Gabriel Kafure da Rocha*

\section{RESUMO}

A investigação da liberdade como tornar-se a si mesmo em Kierkegaard tem sido amplamente debatida por filósofos e comentadores europeus. Nesse contexto, é possível dizer que algumas tendências analíticas da meta-ética como as de Rudd e Davenport se contrapõem as interpretações francesas de Vergote e Ricouer. Nesse sentido, pretende-se fazer uma análise da questão clássica da subjetividade em Kierkegaard: escolher a si mesmo para tornar-se um indivíduo autêntico e livre.

PALAVRAS-CHAVE: Kierkegaard. Tornar-se. Escolha. Liberdade.

\begin{abstract}
The research of freedom to become himself in Kierkegaard has been widely debated by philosophers and European commentators. In this context, one can say that some analytical tendencies of meta-ethics like Rudd and Davenport are opposed interpretations of the French interpratition of Vergote and Ricouer. In this sense, it is intended to analyze the classic question of subjectivity in Kierkegaard: choose yourself to become an authentic and free individual.
\end{abstract}

KEYWORDS: Kierkegaard. Becoming. Choice. Freedom.

\footnotetext{
* Gabriel Kafure da Rocha, doutorando no Programa Integrado de Doutorado em Filosofia (UFPB-UFRN-UFPE) e Professor de Filosofia do Instituto Federal do Sertão Pernambucano.
} 


\section{Considerações iniciais}

O presente artigo pretende discutir a ética da liberdade em Kierkegaard, examinando o conceito de subjetividade como processo de tornar-se si mesmo. A expressão vorde sig selv, "tornar-se um si mesmo" (VATER, 1997) remete a uma ideia importante no pensamento kierkegaardiano. Na obra $A$ doença para a morte, de 1849, é dito que: "O si mesmo é a síntese consciente de infinitude e finitude, que se relaciona consigo mesmo, cuja tarefa é tornar-se si mesmo"1. Significa dizer que o si mesmo pode ser considerado como o espírito, e também como a relação do indivíduo consigo mesmo. Não é um ele ou um ela: é o quê e o quem das coisas. Não é algo que possa ser reduzido ao conhecimento de um conceito. É a própria existência que nunca cessa de devir.

Segundo Kierkegaard, o homem é uma síntese de liberdade e necessidade, ou melhor, uma sintetização, conforme Valls (2012), pois se trata de um processo em curso. Mas o self ou si mesmo, segundo o filósofo, não é a síntese, isto é, a relação entre dois termos, mas sim a relação que tem referência consigo mesma. O si mesmo precisa fazer o seu movimento entre a possibilidade e a realidade na medida em que o indivíduo se dá conta de sua tarefa (Opgave) no mundo. Nesse sentido, quanto mais o indivíduo percebe que o seu conhecimento subjetivo é infinito, mais a infinitude dialética entre a possibilidade e a realidade de ser um si mesmo demonstra-se na relação entre o tornar-se e o ser capaz de. Essas dimensões inicialmente parecem uma só, mas no decorrer do movimento intelectual kierkegaardiano, entre 1844-1846, vai-se demonstrando que é preciso uma distinção entre essas categorias de forma a edificar a tarefa de tornar-se um cristão no aspecto ético-religioso.

A obra kierkegaardiana que representou primeiramente a comunicação indireta do ético foi Enten Eller, A alternativa, de 1843 (na tradução espanhola: $O$ lo uno, o lo outro). Nela, o estádio ético não consiste simplesmente num aspecto especulativo do conhecimento de si, pois existe um ir além que não nega, mas supera o mero debruçar-se intelectualmente sobre si mesmo, numa atitude de escolha e decisão entre um e outro estádio ${ }^{2}$, por uma vida mais estável e livre. O indivíduo ético, que escolheu a si mesmo nesse estádio, decide ir além

\footnotetext{
1 Tradução nossa livre do dinamarquês "Selvet er den bevidste Synthese af Uendelighed og Endelighed, der forholder sig til sig selv, hvis Opgave er at vorde sig selv", frase célebre de Kierkegaard e que pode ser encontrada virtualmente em Sygdommen til dфden. Samlede Verker (Obras completas). Disponível em www.sks.dk (acesso em 06 jun 2014).

2 Categoria kierkegaardiana fundamental que designa as esferas da vida. Chama-se estádio por não pressupor estados de evolução. Nesse sentido, é preciso respeitar a escolha de cada estádio, seja estético, religioso ou ético, sabendo que todos os estádios estão imbricados nos caminhos da vida.
} 
do moralismo da cristandade que representa a sociedade cristã da aparência e da grande massa, não promovendo uma autenticidade subjetiva e ético-religiosa. Por meio dessas ideias, do pseudônimo Juiz Wilhem, um eticista por excelência, mostra-se que a escolha ética se dá entre paradoxos da razão. Diz ele:

Essa expressão da liberdade, e esse é o mesmo caso do mal - é porque é apenas enquanto como eu quero isso. Isso de forma alguma diminui as categorias de bom e mal para meramente subjetivas. Ao contrário, a absoluta validez dessas categorias é declarada. O bom é o em-si e para-si, colocado pelo si mesmo e isso é a liberdade. (KIERKEGAARD, 1987, p. 221 - grifos nossos)

Tornar-se livre na sua repetição faz prosseguir para os conceitos de liberdade e de ética no sentido em que há uma possibilidade de passagem para uma derivação de uma relação entre a dogmática ${ }^{3}$ (ética segunda, que promove uma especulação sobre a questão do pecado e da revelação) e a ética primeira, ética ideal e universal, mas que está presa a questões da temporalidade como efemeridade ou eternidade, como se mostra em Begebret Angest, $O$ conceito de angústia (1844). Nesse livro, na medida em que o indivíduo assume o processo de tornar-se um si mesmo, ele se reconhece na edificação (Opbyggelig) da sua subjetividade. Esta obra é descrita então pelo pseudônimo Vigilius Haufniensis, um vigilante da interioridade que critica a visão alemã da subjetividade como uma autoconsciência leviana e que supostamente não leva em conta a tarefa ética, se restringindo somente a uma ontologia.

Tal como foi visto no Afsluttende uvidenskabelig Efterskrift til de philosophiske Smuler, Postscriptum conclusivo não-científico às Migalhas filosóficas (1846), onde a palavra ética é citada por volta de 71 vezes e que acaba por isso sendo aludida como a mais elevada das tarefas subjetivas. Essa obra, que supostamente foi escrita pelo pseudônimo Johannes Clímacus, é tida como obra central do ponto de vista do estádio ético, tanto que Climacus representa a ideia conceitual da relação e das possibilidades entre viver o pensamento e pensar a existência, e o próprio Kierkegaard sugere que, entre todos os pseudônimos, este é um dos que mais identifica o seu si mesmo.

Nesse sentido, essas noções kierkegaardianas podem ser conjugadas para tentar resolver o problema ético de aceitação do tornar-se um pensador subjetivo que promova uma explicação para as reações humanas, que variam desde a ansiedade e a ironia, e que dessa

3 Quando Kierkegaard se refere à palavra dogma, ele de certa forma tenta tirar o estigma da palavra. Dogma, para ele, representa a característica fundamental de uma religião ou ideologia. Assim que a dogmática seria o estudo da característica fundamental da ética cristã. Essa palavra consistiu também numa disciplina ofertada entre 1837-139 por um dos professores de Kierkegaard chamado Martesen. 
forma possam propor a realização ética da virtude da liberdade. A ética refere-se à vida prática, na qual se insere a edificação. Nesse contexto, Kierkegaard diz que a edificação é seriedade (Alvor), isto é, um cuidado com a realidade, pois a realidade concreta se dá com a relação com o próximo, e nisso o indivíduo mostra que na sua relação com a subjetividade há uma grande importância da maneira como o outro influencia a edificação desse indivíduo. Logo, muitas vezes o sujeito tenta se libertar dos paradoxos entre sua maneira de se conceber no tempo e as assujeitações que recebe da sistemática das inter-relações, de forma que se mostra necessário exercitar-se na tarefa do tornar-se.

\title{
2 Kierkegaard entre analíticos e continentais
}

Numa compreensão da ética kierkegaardiana, é possível encontrar desde uma antropologia filosófica até tendências éticas como consequencialismo, deontologismo ou adeptas de outros estudos éticos. Há diversas justificativas que até então parecem não estar ligadas à relevância da pergunta kierkegaardiana: o que faço quando sei o que devo fazer, mas deixo de fazê-lo? ${ }^{4}$ A maioria dos filósofos modernos colocou como se a tarefa da filosofia prática consistisse na apresentação de respostas positivas para essas questões. Kierkegaard, porém, a partir do contexto em que viveu no século XIX, ofereceu outra estratégia: apresentar diferentes posições conceituais por meio dos pseudônimos, colocando diferentes perspectivas da subjetividade, sempre apontando para escolhas dentre as quais o ser humano tem de optar a fim de ser livre.

\begin{abstract}
A verdadeira liberdade consiste, naturalmente, em dedicar-se ao gozo e contudo conservar sua alma intacta. $\mathrm{Na}$ vida política a verdadeira liberdade consiste, naturalmente, em estar situado no contexto da vida, de tal modo que esta tenha uma validade objetiva para a gente, e aí conservar a mais íntima, a mais profunda vida pessoal, que bem pode se mover sob estas condições e relações, mas é, contudo, até certo ponto, incomensurável com elas. (KIERKEGAARD, 1991, p. 143).
\end{abstract}

É por essa verdadeira liberdade que todo indivíduo deve refletir a sua existência. Para Kierkegaard, o político é muitas vezes traduzido como o religioso, pois é nesse aspecto que se dá a dimensão social de seu pensamento. Nesse sentido,

4 Kierkegaard discutiu isso como a possibilidade de definição de pecado na antiguidade grega, que ele demonstrou como uma falta de noção de pecado devido a noção de Villien (vontade). 
A verdadeira liberdade é para ser encontrada através da experiência da transformação social - e não como na mera negação da experiência. A problemática fundamental da liberdade não tem a ver com a constituição transcendental do si mesmo, mas com o si mesmo em relação aos outros. (PATTISON, 2004, p. 213).

A Ética, na perspectiva kierkegaardiana, é justamente essa experiência social que está entre os estádios da estética e da religião, estádios subjetivos por excelência. O ético é a consciência da causalidade do mundo que escapa ao nada no qual a subjetividade se angustia. Por isso, se pretende eticamente uma realidade efetiva, para mostrar a idealidade como tarefa dentro do que se pressupõe como posse das condições nas quais o homem seja capaz de realizá-la. No entanto, evidencia-se que a Ética se desenvolve entre as contradições da vida, justamente por tornar nítidas as dificuldades, possibilidades e impossibilidades para seu prevalecer. Segundo Kierkegaard, a ética aponta para a problemática de julgar, mas não de criar, pois esta dimensão cabe à estética. Sendo assim, o julgar deve também se alinhar ao tornar no sentido de edificar tanto o próximo como o si mesmo. Dessa forma, ao propor esse exercício de pensamento, a filosofia kierkegaardiana mostra sua importância como fundamento das filosofias existenciais que por isso, podem considerar a existência do indivíduo em seu papel universal e ético.

Resta ainda pontuar que as obras A alternativa, Conceito de angústia e o Postscriptum, dentro dessa perspectiva ética da liberdade, consistem em obras kierkegaardianas de suma importância. "No Conceito de angústia por si, [...], o ponto de indiferença, como isto visto, é entre as dimensões de natureza e liberdade." (PATTINSON, 2004, p. 6). Talvez seja por essa indiferença, a que naturalmente não se dá a devida importância, que seja possível encontrar realmente um diferencial na edificação ética do indivíduo.

Já que em A alternativa (Parte II) dá-se justamente o movimento de passagem entre o estético e o ético, havendo então um diálogo ético muito interessante entre as ideias dos pseudônimos Wilhem e Vigilius, tal qual nos mostra Vergote. Dessa dialética do dilema ético da liberdade surge a ideia do salto, categoria essencial para a filosofia kierkegaardiana:

Mas Wilhelm não é Vigílio Haufniensis. Ele não tem o talento dialético necessário ao nosso estudo de todos os aspectos de uma instância intermediária. E por isso ainda não estudou a Philosophia do Magister Kierkegaard para aprender a sua "teoria do salto". (VERGOTE, p. 409) 
Dessa mesma forma, a partir do momento que Climacus é envolvido nesse debate, por meio do Postscriptum, é possível engendrar um equilíbrio ético no debate da problemática a seguir. Tanto que questões como a vontade, reconciliação, responsabilidade são de fato fundamentais para a presente pesquisa. É o que se caracteriza como transição da liberdade relativa para a absoluta e todas as rupturas e saltos que envolvem essa passagem. Por isso, o sujeito precisa exercitar-se na subjetividade do Postscriptum para encontrar na interioridade a vocação ética.

Como a possibilidade pode ser encarada como aspecto transcendental da liberdade, o homem angustia-se nessa construção; aliás, nesse aspecto é preciso determinar a angústia justamente como problema diante da liberdade. Nessa síntese entre necessidade e possibilidade, a angústia possui uma ambivalência tida como simpatética na medida em que se relaciona de maneira positiva com o pathos, sendo a tradução da experiência interior; mas também tem um caráter antipatético no abandono da totalidade para pensar o si mesmo. Nessa ambiguidade, por um lado, a angústia desperta a liberdade, por outro, também suscita o problema do temor.

Sobre a questão do Tornar-se, Anthony Rudd investiga que existe uma necessidade de caracterizar essa ação do tornar-se rumo a uma variedade de descrições de suas ações. A inteligibilidade da ação que faz parte dessa narrativa pode ser descrita como um projeto de vida. O filósofo Bernard Williams diz que são as motivações futuras que norteiam cada projeto pessoal. Nesse sentido, há um fundamento na categoria do desejo de cada um que vai "sendo assim desenhado - de modo distintamente kierkegaardiano - como noção e caráter que Williams critica de Parfit por nos dissolver em eus sucessivos à curto prazo" (RUDD, 1993, p. 86 - grifos nossos).

O que ocorre, de fato, é que um indivíduo não consegue negar aquilo que foi e, por isso, não pode simplesmente criar um novo eu. Eis aí a questão ética da habituação ou da causalidade em que se edifica a subjetividade do tornar-se. Rudd lembra o caso do "nobre russo", que por viver nos dias socialistas, decidiria se camuflar como um socialista, mas os seus ideais são suspeitos e traem-se a cada decisão ética, chegando a contradizer seus verdadeiros ideais nobres. Logo, não é tão fácil lidar com um “eu ideal”, pois é preciso aceitar a contradição da realidade ética entre a realidade e a idealidade. Rudd chega então a citar Ricoeur, cujo pensamento é também importante para o processo de análise, principalmente do Conceito de angústia, como será mostrado mais à frente. Segundo Rudd, um pingo de relativismo cai em todas as histórias da vida de uma pessoa. Tanto é assim que, para Ricoeur, 
isso seria uma "plurivocidade pertencente ao sentido da ação humana" (RICOEUR apud RUDD, 1993, p. 90).

Dessa forma, a relação plural de sentidos em que os projetos pessoais bem como as virtudes individuais devem estar em harmonia para que o indivíduo se desenvolva autenticamente. Pois, caso não estejam assim postos, o indivíduo tende a cair em subjetivismos irracionais e em escolhas arbitrárias. Uma ética substancial deriva de compromissos sérios com os projetos pessoais de tal forma que "Kierkegaard, como os aristotélicos, relaciona projetos e práticas como cenário de desenvolvimento e exercício das virtudes" (Ibidem, p. 99). Talvez, por isso, a própria tarefa do tornar-se seja existencialmente o exercício prático da relação entre ato e potência realizada num contexto ético. As virtudes como coragem, temperança e moderação são necessárias para um desenvolvimento pessoal na medida em que demonstram seu valor como importantes para um ideal comunitário e cívico, pois não adianta ter virtudes só para si, elas devem existir em associação com a amizade e a justiça.

Nesse sentido da justiça, Rudd ainda cita Philippa Foot, filósofa que mostra a necessidade de haver um princípio na subjetividade para que o indivíduo possa agir de maneira justa com ele e seus semelhantes: "Foot pergunta-se por que o indivíduo deveria agir de forma justa [...] um ponto que Kierkegaard faz no seu criticismo social” (RUDD, 1993, p. 105).

Rudd tenta responder a essa questão sugerindo que a benevolência e a simpatia são virtudes equivalentes à piedade e a compaixão, pois, dessa forma, o julgamento de si e o julgamento do outro podem até ser equivocados, mas ainda assim representam uma luta comunitária: "Foot diz que precisamos pensar o nós mesmos 'como voluntários e faixas unidas para lutar pela liberdade e justiça"' (RUDD, 1993, p. 106, grifos nossos). Por conseguinte, a liberdade deve ser uma busca inerente ao ser humano, e por isso deve ser respeitada através da sensibilidade. Rudd sugere então, por último, um diálogo com o filósofo Jonathan Bennet, o qual, por sua vez, sugere que um senso fino de compaixão também deve mostrar que o que leva uma pessoa a exprimir um sentido de benevolência livre e justa é saber que esse caminho necessita amar ao próximo como a si mesmo, não como questão ética fantasiosa, mas da realidade de que há uma universalidade ética na benevolência. Logo, colocar-se fora dessa condição é o que "Bennet observa [...] eles foram cortados de sua condição humana" (Ibidem, p. 107). 
Dessa forma, a tradição anglo-saxônica de interpretação kierkegaardiana pode se mostrar assim muito proveitosa na demonstração do caráter ético de Kierkegaard. Entretanto, no que consta da tradição francesa da leitura do filósofo dinamarquês, há também um comentador fundamental para a análise ética, que é Henry Vergote. Ao escrever o livro Sens et repetition (Sentido e repetição), o pesquisador vai além da leitura da obra A repetição (1843) e se aprofunda principalmente na leitura de Papirers (Papéis soltos editados postumamente). Papirers, mais do que "folhas soltas", dispõe de fragmentos diversos das questões éticas referentes também ao voluntarismo, dom, vocação e a liberdade ao infinito: "ligados entre si livremente sobre qualquer objeto finito que infinitize a finalidade de satisfazer a exigência do polo infinito [...] se não é o 'infinito malvado dos hegelianos', pelo menos é "lamentável infinito" reunido nos Papirer" (VERGOTE, 1982, p. 411).

Com isso, pode-se dizer que as questões da consciência dialética do finito e do infinito, na subjetividade, se elevam de forma que o indivíduo seja consciente e saiba que é preciso agir qualitativamente consigo mesmo e com seu próximo, tanto que Vergote chega a caracterizar um novo tipo de dialética da liberdade em Kierkegaard.

Vergote sugere também que, em Kierkegaard, no desenvolvimento de uma nova dialética é trabalhada justamente a relação entre a possibilidade e a realidade existencial. Justamente nessa relação entre o ser e o pensar que se coloca o sentido de uma invenção moral: "é a representação de uma ética que não deve sua consistência ao ter de conhecer o sentido e a perspectiva que sabe relativizar determinações da moralidade, mas que se expresse na boa vontade" (VERGOTE, 1982, p. 404). Uma dialética autêntica, tal qual a proposta por Kierkegaard, não é um remendo de categorias anteriores propostas por outros pensadores, pois, para Vergote, trata-se justamente de encontrar na subjetividade a tarefa de aceitação da liberdade do si mesmo e do próximo. Logo, há evidentemente problemas de mal-entendidos (Misforstaaelse) na filosofia kierkegaardiana, mas que são justamente consequências de sua metodologia irônica da comunicação indireta e complexa entre os estádios e pela realidade da não separação entre eles.

O próprio Rudd reconheceu essa relação indissociável entre estádios, tendo que postular subcapítulos (de seu livro) que tratam da transição promovida entre a ética e os outros estádios: "Kierkegaard on aestheticism and the ethical" (Kierkegaard sobre a estética e a ética) ou "from the ethics to religion" (da ética para a religião). Essa indissociação dos estádios tem a ver com as implicações da unidade da ciência kierkegaardiana e de como ela responde ao desenvolvimento do conceito de reconciliação entre as esferas ou estádios da 
vida, ou seja, na tarefa de criar-se o indivíduo, de certo modo, deve-se escolher um estádio, mas na tarefa de tornar-se, esse indivíduo precisa promover uma reconciliação da sua escolha, de modo que a ética seja a chave de sua autocompreensão e reconciliiação no estádio que tiver escolhido, tendo liberdade de compreender as outras esferas existenciais.

\section{Considerações finais}

Ao distinguir a Ética dos outros estádios, na medida em que separa a realidade situacional de um indivíduo das suas escolhas, que fazem parte todas as contradições e mistérios que constituem o ser humano, a realidade da liberdade no conceito do Ético não se satisfaz com fórmulas e enunciados da razão. Assim:

As diversas ciências se deveriam ordenar, segundo o modo em que se acentua o ser e como a relação com o ser dá a recíproca vantagem. Ontologia e Matemática: a certeza é absoluta - aqui o pensamento e o ser se identificam, mas para um encontro estas ciências são hipóteses. (KIERKEGAARD, 1980, p. 117).

Nesse sentido, alcançar o bem da liberdade é possível desde que a ética não seja uma simples hipótese tais quais as outras ciências, pois é, antes de tudo, um compromisso subjetivo de si com o próximo. Visto isso, pontuam-se, a seguir, algumas questões hipotéticas como delineamento para a questão ética que propõe Kierkegaard: 1 - A dialética da liberdade entre o ser capaz de e o tornar-se está fundamentada na possibilidade de aceitação ética da singularidade do indivíduo; 2 - Nesse sentido, a escolha kierkegaardiana se dá na realidade de que todo indivíduo quer escolher o seu próprio bem; 3 - Mas, para isso, é preciso entender qual é o sentido de haver uma dualidade entre o bem e o mal em toda escolha; 4 - Logo, é preciso entender por que a subjetividade é justamente a escolha de si como verdade e nisso a realidade do salto ético entre os estádios para conhecer a si mesmo e escolher a ética da liberdade.

Assim, considero que a continuidade do tornar-se do indivíduo na tarefa subjetiva é necessária para se deparar com o questionamento na medida em que a subjetividade é verdadeira. Essa questão, evidentemente, gira em torno do movimento kierkegaardiano de tornar-se e ser capaz de.

Primeiramente, é preciso entender que para tornar-se o indivíduo deve estar pronto para perder-se, para depois reencontrar a si mesmo e esse é um movimento 
caracteristicamente ético. Ser capaz-de é uma tarefa subjetiva na medida em que exige a capacidade de saltar entre os estádios, ou seja, a capacidade de tornar a escolha em decisão efetiva.

Por isso, no projeto kierkegaardiano, valoriza-se mais o tornar-se. Pelo tornar-se se pode identificar o problema entre a subjetividade e a individualidade e o questionamento de sua equivalência ou não, pois a subjetividade exige a decisão e a repetição ${ }^{5}$, e a individualidade consiste em converter algo do interior na tarefa da liberdade.

A ética, estando entre o Homem e Deus (também caracterizada pela palavra Teantropia de Vergote), mostra que o tornar-se da subjetividade está além da objetividade do sistema, da igreja, da família e da política. A subjetividade é uma categoria ambivalente, de tal forma, que suas variações como verdade, ironia e ética exigem um estudo minucioso. Logo, a ética da subjetividade kierkegaardiana vê que a verdade é uma ironia ética. Entretanto, essa verdade é posta entre a interioridade e a identidade autossuficiente. É na concepção da subjetividade como interioridade que está a possibilidade de entender a alteridade em que o eu é a consciência de que existe o tu. Por isso, se o eu Kierkegaardiano se desdobra em pseudônimos para ver a si como um outro, é porque, de fato, o eu se perde para reencontrar a si mesmo; a identidade e a singularidade que o si mesmo percebe são diferentes, pois a identidade é autossuficiente e a singularidade precisa do outro. Assim, a existência concebida no interior da consciência mostra-se como contraditória, fragmentada, angustiada, etc., tanto que a linguagem, ao demonstrar o paradoxo, mostra também que a racionalidade filosófica por si só não consegue exprimir o pathos da existência.

A tarefa ética kierkegaardiana pode muitas vezes ser encarada como uma passagem entre estádios, mas é justamente nessa passagem que se dá o salto, no sentido que se sai da idealidade para a realidade. Nisso, o pathos ético está além das leis, pois é a espontaneidade do transbordamento da interioridade: "Por isso, somente quem edificou a si mesmo na interioridade é capaz de constituir-se em maturidade e capaz de abnegar-se de si como doação do excesso de si, ou do transbordamento de si” (MIRANDA, 2013, p. 12).

5 Apesar de Kierkegaard conferir uma obra sob a temática, A repetição (1843), no presente caso, ela está ligada à ideia da contraposição com o hábito. A repetição caminha para frente, mas para isso ela tem que se diferenciar do hábito. Segue-se que "Hábito" é devidamente utilizado apenas como mal, de tal forma que, por ele, é designado tanto como uma continuidade em algo que em si mesmo é um mal ou uma repetição tão teimosa de algo em si mesmo que seria inocente e que se torna um mal pequeno por causa dessa repetição. Assim, hábito sempre designa algo sem liberdade, mas, “assim como não se pode fazer o bem, exceto na liberdade, assim também [...] nunca podemos falar de hábito em relação ao bom”. (KIERKEGAARD, 1987, p. 127). 
A responsabilidade é a essência da subjetividade e nisso seus sinônimos - decisão, paixão infinita e evidentemente a verdade - podem ser também, pois é uma decisão de escolher a si mesmo, uma paixão infinita pela vida e uma verdade de amor ao próximo. $\mathrm{O}$ importante é não confundir essa categorização com uma subjetividade abstrata. É como um jogo da imaginação que se reduziria a uma pura relação entre ser e pensamento. Isso é uma lógica do tipo tautológica em que não se afirma o "eu" pensante, logo, não há um pensador subjetivo, caindo numa metafísica. Isso dissolve a responsabilidade do indivíduo singular de tal modo que ele simplesmente repete o que o outro já fez e nisso, também se ressalta, não há um conceito dialético kierkegaardiano em que a dialética ${ }^{6}$ da contradição supera e destrói. A dialética kierkegaardiana não tem síntese porque tem saltos entre o eu e o outro, logo, é mais do que uma dialética entre o interior e o exterior, porque mostra a singularidade que há em um e no outro.

No conceito de essência encontra-se a existência. Por isso, só há subjetividade e alteridade: Deus é a subjetividade pura, pois se fosse um ser objetivo, cairia no relativismo. O que ocorre de fato é que Deus é uma subjetividade perfeita e o indivíduo está na tarefa de tornar-se uma obra de arte: o indivíduo está num processo de lapidação que não segue uma lógica sistemática, mas uma não-lógica paradoxal. O âmago do individuo singular é ter caráter e personalidade de tal modo que não deixe que acidentes e corrupções desviem sua tarefa de ser um si mesmo:

Mas o que é o si mesmo? Se eu quero falar num primeiro momento, a primeira resposta para isso é? Na maior abstração de tudo, o si mesmo ainda é também a mais concretude de tudo - é a liberdade. (KIERKEGAARD, 1987, p. 214).

A relação entre ser, essência e existência, em Kierkegaard, mostra então uma inacessibilidade em que o devir está o tempo todo fazendo com que o ser seja um tornar-se livre. Ele se utiliza desse argumento para afirmar que Deus é a essência e que o que se fala disso é a relação entre ser e existir. Não se pode provar a existência de Deus, visto que sobre isso só se pode silenciar. A existência tem essa qualidade de tal modo que seja uma aspiração contínua, um devir que é o tornar-se a própria verdade, ou seja, é sair da dicotomia entre ser e pensar, e dizer que o pensar é o ser que é a verdade. Portanto, há uma concretude ética de ser o que se pensa de melhor e mais divino, e esse é um risco que todo indivíduo deve assumir.

6 Torna-se necessário enfatizar novamente que a dialética kierkegaardiana é tão diferente do idealismo alemão que pode chegar a ser considerada como uma dialética que não opera por sínteses, mas sim por saltos. 


\section{Referências}

\section{Primárias}

KIERKEGAARD, S. Temor e tremor. São Paulo: Abril, 1984. Vol. XXXI. (Col. Os Pensadores).

KIERKEGAARD, S. Ponto de vista explicativo da minha obra de escritor. Lisboa: Edições 70, 1986.

KIERKEGAARD, S. O conceito de ironia constantemente referido a Sócrates. Petrópolis: Vozes, 1991.

KIERKEGAARD, S. Either/or. Trad. Hong. Nova Jersey: Princeton University, 1993.

KIERKEGAARD, S. Concluding Uncientific Postscriptum to Philosophical fragments. (Trad. Hong). Nova Jersey: Princeton University, 1993.

KIERKEGAARD, S. O lo uno o lo outro - Um fragmento de vida I. Madrid: Editorial Trotta, 2006.

KIERKEGAARD, S. O lo uno o lo outro - Um fragmento de vida II. Madrid: Editorial Trotta, 2007.

KIERKEGAARD, S. Postscriptum no científico y definitivo a Migajas filosóficas. Santa Fé: Universidad Iberoamerica, 2008a.

KIERKEGAARD, S. La enfermedad mortal. Trad. Demetrio Rivero. Madrid: Trotta, 2008b.

KIERKEGAARD, S. O conceito de angústia. Trad. De Álvaro Valls. Petrópolis: Vozes, 2010.

KIERKEGAARD, S. Pós-escrito conclusivo não-científico às Migalhas filosóficas. Trad. de Álvaro Luiz Montenegro Valls. Petrópolis: Vozes, 2012. Vol I.

Comentadores efetivamente consultados

ALMEIDA, Jorge. Ética e subjetividade. Anais da XIII Jornada Internacional de Estudos de Kierkegaard da SOBRESKI - Sociedade Brasileira de Estudos de Kierkegaard. Vitória da Conquista: UESB, 2013. Disponível em <http://periodicos.uesb.br/index.php/jieks/article/view/2160> Acesso em 01 de maio de 2014.

DAVENPORT; RUDD. Kierkegaard after MacIntyre. Illinois, USA: Carus Publishing Co. 2001.

FERRO, Nuno. Estudos sobre Kierkegaard. São Paulo: LiberArs, 2012.

MALANTSCHUK, Gregor. Kierkegaard's Way to the Truth. An Introduction to the Autorship of Søren Kierkegaard. Montreal: Inter Editions, 1987.

PATTISON, George. Kierkegaard - religion and the nineteenth-century crisis of culture. 
Cambridge, UK: Cambridge University press, 2004.

RICOEUR, Paul. A região dos filósofos. São Paulo: Edições Loyola, 1996. Leitura 2.

RICOEUR, Paul. Le Mal: un défi à la philosophie et à la théologie In: Lectures 3, Aus frontières de la philosophie, tr. Personal. G. Zapata, SJ. Ed. Seuil, Paris, 1994, 211-233.

RUDD, Anthony. Kierkegaard and the limits of the ethical. Oxford: Oxford University Press, 1997.

VALLS, Álvaro. Kierkegaard - cá entre nós. São Paulo: LiberArs, 2012.

VERGOTE, Henri-Bernard. Sens et répétition. Paris, Cerf/Orante,1982. Vol. II.

STEWART; VALLS. Polémica en torno a la figura de Lessing en Kierkegaard. El Arco La Lira y El Arco y la Lira. Tensiones y Debates, N. 1. Argentina: Grupo de Acción y Concepto. 2013. Disponível em: <http://www.revistaarcoylira.com.ar/articulo2.pdf> Acesso em 11-05-2014.

\section{Dicionários}

VATER, P. Dansk-spansk Ordbog. Copenhagen: Gyldendal, 1997.

\section{Comentadores a serem consultados}

ADORNO, Theodor. Construcción de lo estético. Trad. Joaquim Chamorro Mielke. Madrid: Ed. Akal, 2006.

CLAIR, Andre. Kierkegaard: penser le singulier. Paris: Les Editions du Cerf, 1993.

GOUVÊA, Ricardo. A paixão pelo paradoxo. São Paulo: Fonte Editorial, 2006.

MARINO, Gordon. Cambridge Companion to Kierkegaard. Cambridge: Cambridge University Press, 2006.

MACKEY, Louis. Kierkegaard: a kind of poet. Philadelphia: University of Pennsylvania Press, 1971.

PAUlA, Márcio G. de. Subjetividade e objetividade em Kierkegaard. São Paulo: Annablume, 2009.

POLITIS, H. Kierkegaard vocabulaire. Paris: Ellipses Edition Marketing, 2002.

VALLS, Alvaro L. M. Entre Sócrates e Cristo: ensaios sobre a ironia e o amor em Kierkegaard. Porto Alegre: Edipucrs, 2000.

WAHL, Jean. Études kierkegaardiennes. Paris: Vrin, 1974. 